doi: $10.2306 /$ scienceasia1513-1874.2013.39.230

\title{
Total number, virulence genes, and heterogeneity of Vibrio parahaemolyticus in a single shellfish
}

\author{
Junthip Thongchan ${ }^{\mathrm{a}}$, Phuangthip Bhoopong ${ }^{\mathrm{b}}$, Mingkwan Yingkajorn $^{\mathrm{a}, \mathrm{c}}$, Mitsuaki Nishibuchi $^{\mathrm{d}}$, \\ Varaporn Vuddhakul ${ }^{\mathrm{a}, *}$ \\ a Department of Microbiology, Faculty of Science, Prince of Songkla University, Hat Yai, Songkhla, Thailand \\ b School of Allied Health Sciences and Public Health, Walailak University, Nakhon Si Thammarat, Thailand \\ c Department of Biomedical Science, Faculty of Medicine, Prince of Songkla University, Hat Yai, Songkhla, \\ Thailand \\ d Centre for Southeast Asian Studies, Kyoto University, Yoshida, Sakyo-ku, Kyoto
}

*Corresponding author, e-mail: varaporn.v@psu.ac.th

\begin{abstract}
Infection by Vibrio parahaemolyticus is established if seafood contaminated with pathogenic strains of this bacterium at a sufficiently high dose is consumed. We reported recently that $V$. parahaemolyticus isolates from $67 \%$ of patients constituted a homogeneous population of a pathogenic strain and a heterogeneous population of V. parahaemolyticus varying in the serotype and/or the virulence gene profile found in $33 \%$ of the patients. To assess the possibility that this result was due to the dominant presence of a homogeneous strain of $V$. parahaemolyticus in shellfish, we enumerated and characterized $V$. parahaemolyticus in shellfish samples including three kinds of molluscan bivalves. Using CHROMagar Vibrio isolation medium, presumed total Vibrio strains and presumed V. parahaemolyticus in each of 52 shellfish samples were enumerated. The highest numbers of presumed total Vibrio strains and presumed V. parahaemolyticus were detected in bloody clam and mussel, respectively. There was no correlation between the number of presumed total Vibrio strains and that of presumed V. parahaemolyticus. Five to ten strains of $V$. parahaemolyticus isolated from each shellfish sample were characterized. Virulence genes ( $t d h$ and $t r h$ ) could be detected in none of the isolated strains. Diversities in the serotype and DNA fingerprints were confirmed among the isolated strains from a single shellfish sample representing six different shellfish groups. We therefore conclude that most of the single shellfish harbour a pathogenic strain-bearing heterogeneous population of $V$. parahaemolyticus and the concentrations of pathogenic strains are low.
\end{abstract}

KEYWORDS: enumeration, serotype, genotype, CHROMagar

\section{INTRODUCTION}

Vibrio parahaemolyticus is a halophilic bacterium that causes seafood-borne gastroenteritis ${ }^{1}$. The clinical symptoms develop within 4-96 h after consumption of seafood contaminated with pathogenic strain of this bacterium at or higher than an infectious dose $\left(2 \times 10^{5} \text { to } 10^{9} \text { organisms of pathogenic strains }\right)^{2}$. The symptoms include abdominal cramps, nausea, vomiting, headache, diarrhoea, mild fever, and chills ${ }^{3}$. Only $V$. parahaemolyticus strains that produce one or both of two important virulence factors, a thermostable direct haemolysin (TDH) and a TDH-related haemolysin, have been considered to be pathogenic strains $^{4,5}$. These haemolysins are encoded by the $t d h$ and $t r h$ genes, respectively; either $t d h$, trh or both genes are present in most clinical isolates of V. parahaemolyticus ${ }^{6}$. However, only $3-6 \%$ of environmental isolates harbour these genes ${ }^{7,8}$. A clas- sification based on combination of the serotypes of two antigens, somatic $\mathrm{O}$ and capsular-like $\mathrm{K}$, have been established using clinical strains and serves as a useful tool in epidemiological investigations ${ }^{9}$. At present time $13 \mathrm{O}$ and $74 \mathrm{~K}$ serotypes have been reported. However, there are many environmental strains of $V$. parahaemolyticus that are untypeable to these existing serotypes because environmental strains have not been included in establishment of the $\mathrm{O}: \mathrm{K}$ serotype. Since 1996, the increase in incidence of gastroenteritis due to $V$. parahaemolyticus $\mathrm{O} 3: \mathrm{K} 6$ has been reported from many countries in Asia, America, Africa, and Europe ${ }^{10}$. These strains are considered to belong to a pandemic clone and the strains belonging to some other serotypes (O1:K25, O4:K68, O1:KUT, etc.) are considered to have diverged from the $\mathrm{O} 3: \mathrm{K} 6$ pandemic clone ${ }^{11,12}$.

Results of the attempts to isolate the O3:K6 pandemic strains from shellfish in Songkla Province 
in southern Thailand demonstrated that the O3:K6 pandemic strains are accumulated in molluscan bivalves but not in other shellfish ${ }^{8,13}$. Investigations of clinical isolates of $V$. parahaemolyticus from Hat Yai Hospital, Songkla Province have demonstrated that $67 \%$ of patients were infected with a homogeneous population of pathogenic strains of $V$. parahaemolyticus belonging to a single $\mathrm{O}: \mathrm{K}$ serotype and most of these patients were infected by the strains belonging to the pandemic O3:K6 clone (hereinafter abbreviated as O3:K6 pandemic strains) ${ }^{14}$. However, a heterogeneous population varying in serotype and virulence gene profile were found from the rest $(33 \%)$ of the patients. To investigate whether this result was due to consumption of molluscan bivalves containing a homogeneous population of $V$. parahaemolyticus bearing a pathogenic strain at or higher than the infectious dose with an ability to subsequently predominate in human digestive tracts, we examined total numbers, virulence genes, and homogeneity/heterogeneity represented by the $\mathrm{O}: \mathrm{K}$ serotype (and DNA fingerprints when needed) of $V$. parahaemolyticus strains isolated from single shellfish samples.

\section{MATERIALS AND METHODS}

\section{Enumeration of $V$. parahaemolyticus in shellfish}

Shellfish samples were obtained from morning markets in Hat Yai City, Songkhla Province, Thailand between June and October 2010. They were examined within $1 \mathrm{~h}$ of collection. Their meat was removed and crushed in alkaline peptone water $\mathrm{pH} 8.6$ supplemented with $1 \% \mathrm{NaCl}$ at the ratio of $1: 10$. Then $0.1 \mathrm{ml}$ of each sample was spread on CHROMagar Vibrio (CHROMagar Microbiology, Paris, France) in duplicate and inoculated plates were incubated at $37^{\circ} \mathrm{C}$ for $24 \mathrm{~h}$. The numbers of the total colonies and that of mauve colonies, presumed to be $V$. parahaemolyticus, were counted and their concentrations in the original shellfish in $\mathrm{cfu} / \mathrm{g}$ were calculated. Five to ten mauve colonies were selected for confirmation of V. parahaemolyticus and detection of virulence genes.

\section{Confirmation of $V$. parahaemolyticus and detection of virulence genes}

The mauve colonies on CHROMagar Vibrio medium were presumed to be $V$. parahaemolyticus. To confirm this presumptive identification, the isolated mauve colonies were examined for $V$. parahaemolyticusspecific toxR gene sequence by a PCR method ${ }^{15}$. The test isolate was grown in Luria-Bertani (LB) broth containing $1 \% \mathrm{NaCl}$ with shaking (160 rpm) at $37^{\circ} \mathrm{C}$ overnight. One $\mathrm{ml}$ of the broth culture was centrifuged, and the bacterial cells were washed and resuspended in sterile saline $(0.85 \% \mathrm{NaCl})$. The cell suspension was boiled for $10 \mathrm{~min}$, and the supernatant was obtained by centrifugation, diluted 10-fold in distilled water, and used as the template for PCR amplification. Amplification of the toxR gene was performed using primers T4 and T7 as described previously ${ }^{15}$. Since the urease-positive phenotype of V. parahaemolyticus has been reported to be associated with the presence of the trh gene ${ }^{16}$, all toxR positive isolates were screened for urease activity. Presence or absence of the $t d h$ and $t r h$ genes was examined by PCR using the previously reported primers D3-D5 and R2-R6, respectively ${ }^{17}$. The isolates that exhibited urease activity but were negative for the $t r h$ gene by the PCR assay were examined by Southern blot hybridization using trh probes as described previously ${ }^{18}$.

\section{Serotyping}

Five isolates of $V$. parahaemolyticus from each of six selected shellfish were subjected to $\mathrm{O}: \mathrm{K}$ serotyping. The O:K serotype of each isolate was determined by the slide-agglutination test using anti-O and anti$\mathrm{K}$ antibodies (Denka Seiken, Tokyo). Briefly, the test isolate was grown in tryptic soy broth containing $3 \% \mathrm{NaCl}$ at $37^{\circ} \mathrm{C}$ for $18 \mathrm{~h}$, and the bacterial cells were suspended in saline $(3 \% \mathrm{NaCl})$. The bacterial cell suspension was subjected to agglutination with specific anti-K antibodies to determine the K serotype. For determination of the $\mathrm{O}$ serotype, the bacterial cell suspension was autoclaved at $121^{\circ} \mathrm{C}$ for $30 \mathrm{~min}$. Autoclaved bacterial cells were subjected to agglutination with specific anti-O antibodies.

\section{Arbitrarily primed polymerase chain reaction (AP-PCR)}

In order to determine DNA profiles of $V$. parahaemolyticus, DNA of each test strain was extracted by the phenol-chloroform extraction method ${ }^{19}$. AP-PCR was performed using primer 2 (5'-GTTTCGCTCC-3') as described previously ${ }^{14}$. Briefly, amplification was performed in a 30- $\mu$ mixture composed of $0.33 \mathrm{mM}$ dNTPs (TaKaRa Biochemicals, Tokyo), 25 ng template DNA, 2.5 U Ex Taq (TaKaRa), 0.83 pmol primer, and $1 \times$ Ex Taq Buffer (TaKaRa). The PCR was performed in a thermal cycler (Program Temp Control System PC-808, Astec Co., Tokyo). The thermocycle was started with a cycle at $95^{\circ} \mathrm{C}$ for $4 \mathrm{~min}$. This was followed by 45 cycles of denaturation at $95^{\circ} \mathrm{C}$ for $1 \mathrm{~min}$, annealing at $36^{\circ} \mathrm{C}$ for $1 \mathrm{~min}$, and extension at $72{ }^{\circ} \mathrm{C}$ for $2 \mathrm{~min}$, in which a transition time of $5 \mathrm{~min}$ was set between the denaturation and annealing, annealing and extension, and extension and denaturation 
Table 1 Meat weight, total number of bacteria and V. parahaemolyticus (VP) detected on CHROMagar Vibrio from single shellfish samples.

\begin{tabular}{|c|c|c|c|c|c|c|}
\hline \multirow{2}{*}{$\begin{array}{l}\text { Seafood samples } \\
\text { (no. of tested samples) }\end{array}$} & \multirow{2}{*}{$\begin{array}{c}\text { Average meat weight } \\
\text { (g/single seafood) }\end{array}$} & \multicolumn{2}{|c|}{ No. of total bacteria $(\mathrm{cfu} / \mathrm{g})$} & \multicolumn{2}{|c|}{ No. of $V P(\mathrm{cfu} / \mathrm{g})$} & \multirow{2}{*}{$\begin{array}{l}\text { Proportion } \\
\text { of } V P(\%)^{\mathrm{b}}\end{array}$} \\
\hline & & Average & Min-Max & Average & Min-Max & \\
\hline Shrimp (10) & $8.5 \pm 0.2^{\mathrm{c}}$ & $1.0 \times 10^{5}$ & $4.0 \times 10^{2}-4.9 \times 10^{5}$ & $5.8 \times 10^{3}$ & $1.0 \times 10^{2}-4.6 \times 10^{4}$ & 5.8 \\
\hline Crab (2) & $34.3 \pm 1.4$ & $1.1 \times 10^{5}$ & $8.0 \times 10^{4}-1.4 \times 10^{5}$ & $1.0 \times 10^{2}$ & $0-2.0 \times 10^{2}$ & 0.1 \\
\hline Mussel (10) & $7.6 \pm 0.7$ & $4.3 \times 10^{5}$ & $8.0 \times 10^{3}-1.5 \times 10^{6}$ & $4.7 \times 10^{4}$ & $1.0 \times 10^{3}-2.1 \times 10^{5}$ & 10.9 \\
\hline Hard clam (10) & $3.8 \pm 0.2$ & $3.0 \times 10^{4}$ & $4.0 \times 10^{2}-1.2 \times 10^{5}$ & $3.2 \times 10^{3}$ & $4.0 \times 10^{2}-1.6 \times 10^{4}$ & 10.6 \\
\hline Bloody clam (10) & $4.1 \pm 0.1$ & $7.7 \times 10^{6}$ & $3.0 \times 10^{3}-7.5 \times 10^{7}$ & $5.1 \times 10^{3}$ & $4.4 \times 10^{2}-3.6 \times 10^{4}$ & 0.07 \\
\hline Squid (10) & $8.6 \pm 0.2$ & $1.6 \times 10^{4}$ & $1.2 \times 10^{3}-4.0 \times 10^{4}$ & $6.6 \times 10^{2}$ & $1.0 \times 10^{2}-2.0 \times 10^{3}$ & 4.1 \\
\hline
\end{tabular}

${ }^{\text {a }}$ Mauve colonies on CHROMagar Vibrio was presumed as that of $V$. parahaemolyticus and this assumption was confirmed as described in the text.

${ }^{b}$ Average no. of $V$. parahaemolyticus/average no. of total bacteria.

${ }^{c}$ Mean \pm SD.

steps. The thermocycle was finished with one cycle at $72{ }^{\circ} \mathrm{C}$ for $7 \mathrm{~min}$. The amplification products were analysed by agarose (1.5\%) gel electrophoresis.

\section{Pulsed field gel electrophoresis (PFGE)}

$V$. parahaemolyticus was grown in LB broth supplemented with $1 \% \mathrm{NaCl}$ at $37^{\circ} \mathrm{C}$ overnight. An agarose plug was prepared by mixing equal volumes of bacterial suspension with melted agarose. Bacterial lysis in an agarose plug was achieved with $950 \mu \mathrm{l}$ lysis solution (containing $50 \mathrm{mM}$ Tris- $\mathrm{HCl}, \mathrm{pH} 8.0$; $50 \mathrm{mM}$ EDTA; $1 \% \mathrm{~N}$-lauryl sarcosine; and $1 \mathrm{mg} / \mathrm{ml}$ proteinase $\mathrm{K}$ ), and the DNA was cleaved for $48 \mathrm{~h}$ and digested with $50 \mathrm{U}$ of Not I restriction enzyme (TOYOBO Co. Ltd., Osaka, Japan). The digested DNA fragments and DNA markers were separated in $1 \%$ Pulsed-Field Certified agarose (Bio-Rad Laboratories, Hercules, CA, USA) using $0.5 \times$ TBE buffer on a CHEF-DRIII system (Bio-Rad). The running condition was set $6 \mathrm{~V} / \mathrm{cm}$ at $14^{\circ} \mathrm{C}$ for $24 \mathrm{~h}$ at a field angle of $120^{\circ}$ and switch times were $1-18 \mathrm{~s}$ for $12 \mathrm{~h}$ and $3-80 \mathrm{~s}$ for $12 \mathrm{~h}$. After completion of the electrophoresis, the gel was stained with ethidium bromide for $30 \mathrm{~min}$, destained in distilled water for $1 \mathrm{~h}$, and photographed using a UV transilluminator.

\section{RESULTS}

\section{Enumeration of $V$. parahaemolyticus in shellfish}

A total of 52 shellfish samples including shrimp, crab, mussel, squid, hard clam and bloody clam were investigated. The average total number of bacteria was the highest for bloody clam at $7.7 \times 10^{6} \mathrm{cfu} / \mathrm{g}$ (ranged from $3.0 \times 10^{3}$ to $7.5 \times 10^{7} \mathrm{cfu} / \mathrm{g}$ ) (Table 1) The average lowest number of bacteria was observed for squid at $1.6 \times 10^{4} \mathrm{cfu} / \mathrm{g}$ (ranged from $1.2 \times 10^{3}$ to $4.0 \times 10^{4} \mathrm{cfu} / \mathrm{g}$ ). Five to ten mauve colonies selected from CHROMagar were confirmed to be $V$. parahae-
Table 2 Serotype of $V$. parahaemolyticus detected in single shellfish samples.

\begin{tabular}{llllll}
\hline Shellfish & \multicolumn{5}{c}{ O:K serotypes } \\
\hline Shrimp & O1:KUT & O4:K34 & O10:K24 & O8:KUT & O8:KUT \\
Crab & O3:K6 & O4:K4 & O4:K4 & O4:KUT & O5:K17 \\
Mussel & O1:KUT & O1:KUT & O1:KUT & O2:KUT & O11:KUT \\
Hard clam & O3:KUT & O4:KUT & O8:KUT & O8:KUT & O8:KUT \\
Bloody clam & O3:K48 & O3:KUT & O4:K63 & O4:KUT & ND $^{\mathrm{a}}$ \\
Squid & O3:KUT & O4:K8 & O4:KUT & O10:K52 & O10:KUT \\
\hline
\end{tabular}

Five isolates of $V$. parahaemolyticus were determined for each shellfish sample.

The O:K serotype of each isolate was determined by agglutination with anti-O and anti-K antibodies.

${ }^{\text {a }}$ Not determined.

molyticus by PCR for each shellfish sample. All the isolates were toxR positive but they harboured neither the $t d h$ nor $t r h$ virulence genes. It was of interest that two isolates were urease positive. The highest number of $V$. parahaemolyticus was detected in mussel $\left(4.7 \times 10^{4} \mathrm{cfu} / \mathrm{g}\right.$ average $)$ and the lowest number was detected in crab $\left(1.0 \times 10^{2} \mathrm{cfu} / \mathrm{g}\right.$ average $)$.

Interestingly, proportion of $V$. parahaemolyticus relative to the total number of bacteria was very high for some molluscan bivalves (10.9\% for mussel, $10.6 \%$ for hard clams) and very low for some molluscan bivalves $(0.07 \%$ for bloody clam) (Table 1$)$.

\section{Diversity of serotype and DNA fingerprints}

Five mauve colonies were selected from a culture plate for each of six selected single shellfish samples and their O:K serotypes were determined (Table 2). Three to five different serotypes of $V$. parahaemolyticus were demonstrated in each of those six single shellfish samples (Table 2). Two to three identical serotypes of $V$. parahaemolyticus were observed in shrimp (O8:KUT), crab (O4:K4), mussel (O1:KUT), and hard clam (O8:KUT) (Table 2). DNA fingerprints of those isolates, including $V$. parahaemolyticus isolates that 


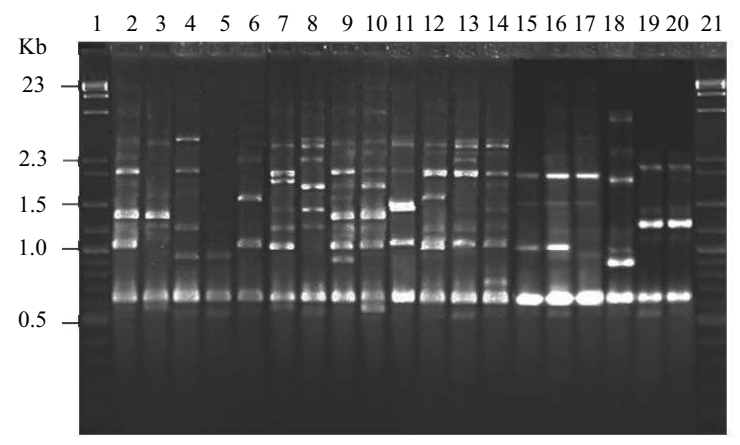

Fig. 1 AP-PCR profile of $V$. parahaemolyticus $(V P)$ isolates from shellfish. DNA fingerprints of identical or nearly identical serotypes of VP isolates from shellfish were determined. The results were obtained with primer 2 .

Lanes 1 and 21: $\lambda$ HindIII +100 bp ladders.

Lane 2: VP PSU 3185, O8:KUT, shrimp ${ }^{\mathrm{a}}$.

Lane 3: VP PSU 3192, O8:KUT, shrimp.

Lane 4: VP PSU 3242, O4:K4, crab.

Lane 5: VP PSU 3244, O4:K4, crab.

Lane 6: VP PSU 3245, O4:KUT, crab.

Lane 7: VP PSU 3098, O4:K63, bloody clam.

Lane 8: VP PSU 3103, O4:KUT, bloody clam.

Lane 9: VP PSU 3100, O3:K48, bloody clam.

Lane 10: VP PSU 3106, O3:KUT, bloody clam.

Lane 11: VP PSU 3195, O4:KUT, squid.

Lane 12: VP PSU 3200, O4:K8, squid.

Lane 13: VP PSU 3201, O10:K52, squid.

Lane 14: VP PSU 3202, O10:KUT, squid.

Lane 15: VP PSU 5312 O1:KUT, mussel.

Lane 16: VP PSU 5313 O1:KUT, mussel.

Lane 17: VP PSU 5314 O1:KUT, mussel.

Lane 18: VP PSU 5309 O8:KUT, hard clam.

Lane 19: VP PSU 5310 O8:KUT, hard clam.

Lane 20: VP PSU 5311 O8:KUT, hard clam.

${ }^{\text {a }}$ Sample from which $V$. parahaemolyticus was isolated.

exhibited the same $\mathrm{O}$ antigen but different $\mathrm{K}$ antigens (one possessed a known $\mathrm{K}$ antigen and another was KUT) were examined next. AP-PCR showed that strains with identical serotypes, O8:KUT (strains PSU 3185 and PSU 3192) and O4:K4 (PSU 3242 and PSU 3244) isolated from shrimp and crab, respectively, produced different DNA fingerprints (Fig. 1 and Table 2). In addition, the V. parahaemolyticus strains isolated from a single shellfish with the same $\mathrm{O}$ antigen but with different $\mathrm{K}$ antigens (O4:K4, O4:KUT isolated from crab; O4:K63 and O4:KUT, $\mathrm{O} 3: \mathrm{K} 48$ and O3:KUT isolated from bloody clam; O4:KUT and O4:K8, O10:K52 and O10:KUT isolated from squid) also exhibited different DNA profiles

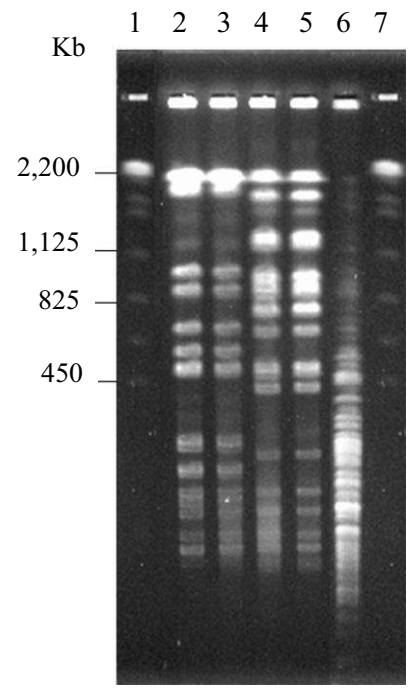

Fig. 2 PFGE confirmation of V. parahaemolyticus (VP) isolates from mussel and hard clam. Both isolates of each serotype (O1:KUT and O8:KUT) of $V P$ obtained from mussel and hard clam were investigated.

Lanes 1 and 7: Saccharomyces cerevisiae PFGE marker.

Lane 2: VP PSU 5312 O1:KUT, mussel.

Lane 3: VP PSU 5313 O1:KUT, mussel.

Lane 4: VP PSU 5310 O8:KUT, hard clam.

Lane 5: VP PSU 5311 O8:KUT, hard clam.

Lane 6: Pseudomonas aeruginosa control strain.

(Fig. 1). However, DNA profiles of two of three identical serotypes, O1:KUT (PSU 5312-5314) and O8:KUT (PSU 5309-5311) of V. parahaemolyticus isolated from mussel and hard clam, respectively, were identical. Confirmation by PFGE revealed that both isolates of each serotype were indistinguishable (Fig. 2).

\section{DISCUSSION}

In the control of seafood safety, the most probable number (MPN) technique is currently used to estimate total number of V. parahaemolyticus. In this study, shellfish, especially three kinds of mollusc, were selected to evaluate the total number of bacteria and that of V. parahaemolyticus. CHROMagar Vibrio was used as the selective isolation mainly medium because it is suitable for detection of $V$. parahaemolyticus ${ }^{20}$. This agar also supports growth of bacteria belonging to most species of the genus Vibrio ${ }^{20}$. These include enteropathogenic Vibrio species such as V. cholerae, $V$. mimicus, and $V$. vulnificus. If the number of total bacterial colonies on CHROMagar Vibrio well reflects the number of colonies belonging to enteropathogenic Vibrio species in general and if the proportion of 
virulent to total population of enteropathogenic Vibrio species, e.g., $t d h^{+}$and/or $t r h^{+}$population versus total population of $V$. parahaemolyticus, is almost constant in a specific sampling site during the sampling season, the relative number of total bacteria on CHROMagar Vibrio may be used as an indicator for enteropathogenic Vibrio species including $V$. parahaemolyticus. If so, the total bacterial count on CHROMagar Vibrio can be an alternative to quantification of enteropathogenic Vibrio species by the MPN estimation-based method. The former method is easier than the latter. However, correlation does not seem to exist between the relative frequencies of total bacterial count and V. parahaemolyticus because the percentage of $V$. parahaemolyticus in total number of bacteria ranged from sample to sample and varied greatly among various seafood species (Table 1).

Bloody clam, mussel and hard clam which are filter feeding shellfish seem to harbour greater numbers of $V$. parahaemolyticus than other shellfish except for shrimp (Table 1). The O3:K6 pandemic strains are accumulated in these molluscan bivalves ${ }^{8,13}$. Vibrio spp. have been demonstrated in various tissues of molluscan bivalves such as clams, oysters and mussels to levels sometimes 100 times that of the overlying water $^{21}$. Wang et $\mathrm{al}^{22}$ demonstrated that $V$. parahaemolyticus was accumulated in digestive glands, gills, adductor muscle and mantle cilia of oysters after artificial inoculation. In this study, the percentage of $V$. parahaemolyticus in total number of bacteria detected in bloody clam was lowest $(0.07 \%)$ but the average number of this bacterium in this shellfish was not much different from those detected in hard clam and shrimp (Table 1). It seems that the number of $V$. parahaemolyticus presented in each kind of single shellfish is high. Consuming a few shellfish can reach an infective dose. Hence enough attention needs to be paid to proper cooking before consumption.

It has been demonstrated that around $3-6 \%$ of $V$. parahaemolyticus isolated from the environment carry the virulence genes $(t d h \text { or } t r h)^{7,8}$. Thus it is not easy to isolate $t d h^{+}$and/or $t r h^{+}$strains from seafood. In this study, we did not obtain any virulent strains of $V$. parahaemolyticus although we usually detect the presence of $t d h^{+}$and/or $t r h^{+}$strains by examining the boiled supernatant of the enrichment culture in our similar studies (V.V. and M.N., unpublished observations). This could be due to the small number of colonies examined per sample in this study. However, two isolates of $V$. parahaemolyticus (PSU 3103 and PSU 3200) obtained from bloody clam and squid, respectively, exhibited urease activity. It has been demonstrated that the presence of trh gene is close to the ure gene on the chromosome of V. parahaemolyticus $^{23}$. Hence Southern blot hybridization with trh probes was performed; those two isolates (PSU 3103 and PSU 3200) did not produce any positive band for $t r h$ (data not shown). Park et $\mathrm{al}^{24}$ demonstrated an insertion sequence-like element present at the end of the DNA region containing the trh and ure genes. Thus it seems possible that the absence of trh gene in these isolates may be associated with an insertion sequence mediated deletion mechanism.

Serotype diversity of this bacterium was demonstrated in all six single shellfish samples examined (Table 2). Two to three identical serotypes of $V$. parahaemolyticus were detected in shrimp, crab, mussel and hard clam. However, DNA fingerprinting revealed those exhibiting identical serotypes were not identical except both isolates of each serotype obtained from mussel (O1:KUT) and hard clam (O8:KUT) (Fig. 1 and Fig. 2). DNA profiles of those isolates obtained from a single shellfish and possessing the same $\mathrm{O}$ but different $\mathrm{K}$ antigens were also different. In addition, the DNA profiles of the isolates that possessed the same serotypes (O4:KUT) but were obtained from different kinds of shellfish (PSU 3103 from bloody clam; PSU 3195 from squid; and PSU 3245 from crab) were different. These indicate that most of the single shellfish harbour heterogeneous population of $V$. parahaemolyticus. The shellfish responsible for $V$. parahaemolyticus infection must contain a pathogenic strain-bearing heterogeneous population of $V$. parahaemolyticus.

In conclusion, the number of V. parahaemolyticus detected in shellfish does not correlate with the total number of bacteria present in each shellfish species. Most of the single shellfish responsible for V. parahaemolyticus infection possibly contain a pathogenic strain-bearing heterogeneous population of $V$. parahaemolyticus; the concentrations of pathogenic strains are low, but they may propagate to infectious doses in shellfish before consumption. If the exact mechanism involved in preferential growth of pathogenic strains in molluscan bivalves is elucidated, it will be useful in detection of potentially hazardous, pathogenic strains in molluscan bivalves.

Acknowledgements: This study was partially supported by funds from the Commission on Higher Education, Thailand, the Thailand Research Fund through the Royal Golden Jubilee $\mathrm{PhD}$ programme (grant no. PHD/0066/2550), Walailak University, and a grant-in-aid of Ministry of Health, Labour and Welfare, Japan. Authors thank Dr Brian Hodgsen for assistance in this manuscript. 


\section{REFERENCES}

1. Yeung PS, Boor KJ (2004) Epidemiology, pathogenesis and prevention of foodborne Vibrio parahaemolyticus infections. Foodborne Pathog Dis 1, 74-88.

2. Nishibuchi M, DePaola A (2005) Vibrio species. In: Fratamico PM, Bhunia AK, Smith JL (eds) Foodborne Pathogens: Microbiology and Molecular Biology. Caister Academic Press, Norfolk, UK, pp 251-71.

3. Blake PA, Weaver RE, Hollis DG (1980) Diseases of humans (other than cholera) caused by vibrios. Annu Rev Microbiol 34, 341-67.

4. Takeda Y (1983) Thermostable direct hemolysin of Vibrio parahaemolyticus. Pharmacol Therapeut 19, 123-46.

5. Honda S, Goto I, Minematsu I, Ikeda N, Asano N, Ishibashi M, Kinoshita Y, Nishibuchi M, et al (1987) Gastroenteritis due to Kanagawa negative Vibrio parahaemolyticus. Lancet 329, 331-2.

6. Nishibuchi M, Kaper JB (1995) Thermostable direct hemolysin gene of Vibrio parahaemolyticus: a virulence gene acquired by a marine bacterium. Infect Immun 63, 2093-9.

7. Deepanjali A, Sanath Kumar H, Karunasagar I, Karunasagar I (2005) Seasonal variation in abundance of total and pathogenic Vibrio parahaemolyticus bacteria in oysters along the Southwest Coast of India. Appl Environ Microbiol 71, 3575-80.

8. Vuddhakul V, Soboon S, Sunghiran W, Kaewpiboon S, Chowdhury A, Ishibashi M, Nakaguchi Y, Nishibuchi M (2006) Distribution of virulent and pandemic strains of Vibrio parahaemolyticus in three molluscan shellfish species (Meretrix meretrix, Perna viridis, and Anadara granosa) and their association with foodborne disease in southern Thailand. J Food Protect 69, 2615-20.

9. Okuda J, Ishibashi M, Hayakawa E, Nishino T, Takeda Y, Mukhopadhyay AK, Garg S, Bhattacharya SK, et al (1997) Emergence of a unique O3:K6 clone of Vibrio parahaemolyticus in Calcutta, India, and isolation of strains from the same clonal group from Southeast Asian travelers arriving in Japan. J Clin Microbiol 35, 3150-5.

10. Nair GB, Ramamurthy $T$, Bhattacharya SK, Dutta B, Takeda Y, Sack DA (2007) Global dissemination of Vibrio parahaemolyticus serotype O3:K6 and its serovariants. Clin Microbiol Rev 20, 39-48.

11. Matsumoto C, Okuda J, Ishibashi M, Iwanaga M, Garg P, Rammamurthy T, Wong HC, DePaola A, et al (2000) Pandemic spread of an O3:K6 clone of Vibrio parahaemolyticus and emergence of related strains evidenced by arbitrarily primed PCR and toxRS sequence analyses. J Clin Microbiol 38, 578-85.

12. Bhuiyan NA, Ansaruzzaman M, Kamruzzaman M, Alam K, Chowdhury NR, Nishibuchi M, Faruque SM, Sack DA, et al (2002) Prevalence of the pandemic genotype of Vibrio parahaemolyticus in Dhaka, Bangladesh and significance of its distribution across different serotypes. J Clin Microbiol 40, 284-6.

13. Vuddhakul V, Chowdhury A, Laohaprertthisan V, Pungrasamee $\mathrm{P}$, Patararungrong N, Thianmontri P, Ishibashi M, Matsumoto C, Nishibuchi M (2000) Isolation of a pandemic clone of a Vibrio parahaemolyticus strain from environmental and clinical sources in Thailand. Appl Environ Microbiol 66, 2685-9.

14. Bhoopong P, Palittapongarnpim P, Pomwised P, Kiatkittipong A, Kamruzzaman M, Nakaguchi Y, Nishibuchi M, Ishibashi M, Vuddhakul V (2007) Variability in properties of Vibrio parahaemolyticus strains isolated from single patients. J Clin Microbiol 45, 1544-50.

15. Kim YB, Okuda J, Matsumoto C, Takahashi N, Hashimoto S, Nishibuchi M (1999) Identification of Vibrio parahaemolyticus strains at the species level by PCR targeted to the toxR gene. J Clin Microbiol 37, 1173-7.

16. Magalhaes M, Takeda Y, Magalhaes V, Tateno S (1992) Brazilian urease-positive strains of Vibrio parahaemolyticus carry genetic potential to produce the TDHrelated hemolysin. Mem Inst Oswaldo Cruz 87, 167-8.

17. Tada J, Ohashi T, Nishimura N, Shirasaki Y, Ozaki H, Fukushima S, Takano J, Nishibuchi M, Takeda Y (1992) Detection of thermostable direct hemolysin gene $(t d h)$ and the thermostable direct hemolysinrelated hemolysin gene (trh) of Vibrio parahaemolyticus by polymerase chain reaction. Mol Cell Probes 6, 477-87.

18. Wootipoom N, Bhoopong P, Pomwised R, Nishibuchi M, Ishibashi M, Vuddhakul V (2007) A decrease in proportion of infections by pandemic Vibrio parahaemolyticus in Hat Yai Hospital, southern Thailand. J Med Microbiol 56, 1630-8.

19. Sambrook J, Russel DW (2001) Molecular Cloning: A Laboratory Manual, 3rd edn, Cold Spring Harbor Laboratory Press, New York, pp 4.55-7.

20. Hara-Kudo Y, Nishina T, Nakagawa H, Konuma H, Hasegawa J, Kumagai S (2001) Improved method for detection of Vibrio parahaemolyticus in seafood. Appl Environ Microbiol 67, 5819-23.

21. Tantillo GM, Fontanarosa M, Di Pinto A, Musti M (2004) Updated perspectives on emerging vibrios associated with human infections. Lett Appl Microbiol 39, 117-26.

22. Wang D, Yu S, Chen W, Zhang D, Shi X (2010) Enumeration of Vibrio parahaemolyticus in oyster tissues following artificial contamination and depuration. Lett Appl Microbiol 51, 104-8.

23. Iida T, Park KS, Suthienkul O, Kozawa J, Yamaichi Y, Yamamoto K, Honda T (1998) Close proximity of the tdh, trh and ure genes on the chromosome of Vibrio parahaemolyticus. Microbiology 144, 2517-23.

24. Park KS, Iida T, Yamaichi Y, Oyagi T,Yamamoto K, Honda T (2000) Genetic characterization of DNA region containing the trh and ure genes of Vibrio parahaemolyticus. Infect Immun 68, 5742-8. 